\title{
Quinolones: structure-activity relationships and future predictions
}

\author{
G. S. TILLOTSON
}

Pharmaceutical Division, Bayer plc, Strawberry Hill, Newbury, Berkshire RG13 1JA

\begin{abstract}
Development of the first clinically useful quinolone - nalidixic acid - occurred in 1962, but the significant breakthrough with this class of agents occurred almost 20 years after the original discovery when the addition of a fluorine molecule at position $\mathrm{C6}$ of the pharmacore created the 'fluoroquinolones'. It has been estimated that over 10000 analogues of nalidixic acid or the fluoroquinolones have now been synthesised. The benefits of some of these new compounds include: oral and parenteral dosing, a much broader spectrum of antibacterial activity, good tissue distribution, improved pharmacokinetic profiles, stability and a comparatively low incidence of adverse effects. This review considers the structure of the core fluoroquinolone molecule, some of the changes that feature on current class members under development, and the effects that these chemical modifications may have on the interaction of these compounds with man.
\end{abstract}

\section{Historical development of the quinolones}

A group of scientists in the laboratories of the Sterling Company, while pursuing new chemical entitites based on the structure of quinine in an effort to expand the armamentarium against malaria, discovered that derivatives of the 1,8-naphthyridine molecule possessed antibacterial activity. By 1962, George Lesher and colleagues had developed nalidixic acid [1]. This was the first clinically useful compound in the series, and by 1964 it was available in the UK for the treatment of urinary tract infections. This narrow clinical indication was a consequence of two factors: the poor serum and tissue concentrations achieved after oral administration, and the limited spectrum of activity, restricted primarily to the Enterobacteriaceae $[1,2]$.

This first 4-quinolone - also known as naphthyridine carboxylic acid - was succeeded by molecules with minor modifications, including compounds such as oxolinic acid, cinoxacin, pipemidic acid and others. However, none of these compounds constituted a major advance in terms of improved antibacterial spectrum or pharmacokinetics, and hence were still restricted largely to the treatment of urinary tract infections. It was not until almost 20 years after the original development of nalidixic acid that there was a significant breakthrough with this class of agents. Koga et al. [3] observed that improvements in

Received 25 Aug. 1995; accepted 3 Oct. 1995. absorption and activity were achieved by making modifications at positions $\mathrm{C} 6$ and $\mathrm{C} 7$ of the pharmacore (Fig. 1). The addition of a fluorine molecule at C6 created the 'fluoroquinolones'. This category of agents is one of the most intensively investigated group of compounds in the field of medicine; indeed, since Lesher's original report, it has been estimated that over 10000 analogues of nalidixic acid or the fluoroquinolones have been synthesised [4]. The benefits of these newer compounds include: oral and parenteral dosing, a much broader spectrum of antibacterial activity, good tissue distribution, improved pharmacokinetic profiles which favour once or twice a day dosing, good stability and a comparatively low incidence of adverse effects. The major breakthroughs have resulted from a markedly improved understanding of the molecule and how its

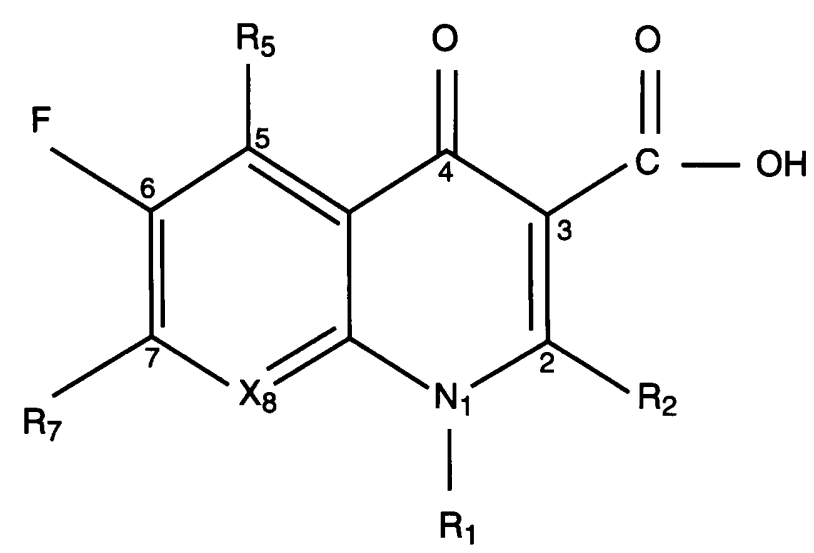

Fig. 1. The quinolone pharmacore. 
structure interacts with both its target site in bacteria and metabolic systems in man.

Despite the plethora of research and publications regarding this class of antimicrobials, only a few have so far been licensed for clinical use. Table 1 shows the agents available in Europe and the USA. The value of structure-activity relationship (SAR) studies should be considered in the context of the approved agents and how certain modifications on new, yet to be licensed widely, molecules may constitute a step forward. The remainder of this review will discuss the core fluoroquinolone molecule and some of the changes that feature on class members under development.

\section{Structure-activity relationships}

Fig. 1 shows the core molecule and the positions at which key changes are engineered. Some of these molecular substitutions should not be altered as they would interface with or reduce markedly the basic mode of action of the drug. These are positions 2,3 and 4 ; at position 2 , a hydrogen moiety is optimal any larger molecular additions may create a steric hindrance at the adjacent positions 3 and 4 which must be a carboxyl group and oxygen molecule, respectively. Binding to the DNA bases occurs at these positions, which are then made available for new hydrogenbinding partners by the action of the enzyme, DNA gyrase. The moiety at position 6 should be small, and a fluorine atom is optimal as it confers between five- and 100 -fold greater potency than any other potential halogen moiety.

The four other positions can receive a wide range of potential substituents. SAR studies have enabled the recognition of features that lead to specific changes, as summarised below:-

position 1 -has some effect on the pharmacokinetics of an agent and exerts control on its overall potency;

position 5-specific moieties substituted at this position have resulted in increased activity against gram-positive bacteria;

Table 1. Fluoroquinolones licensed currently

\begin{tabular}{lc}
\hline Drug & Country in which licensed \\
\hline Enoxacin & UK, USA \\
Norfloxacin & UK, USA \\
Pefloxacin & F \\
Ciprofloxacin & UK, USA, $>120$ countries \\
Ofloxacin & UK, USA, $+>100$ countries \\
Lomefloxacin & J, F, UK, Be, Fin, CH \\
Sparfloxacin & J \\
Tosufloxacin & J \\
Levofloxacin & [UK, USA, now withdrawn] \\
[Temafloxacin] &
\end{tabular}

Be, Belgium; CH, Switzerland; F, France; Fin, Finland; J, Japan; UK, United Kingdom; USA, United States of America. position 7-both spectrum of activity and pharmacokinetics are controlled at this point; five- and sixmembered rings containing a ' $\mathrm{N}$ ' atom yield the most activity;

position 8-pharmacokinetic and specific activity against anaerobic bacteria can be adjusted from this point.

It is intriguing for molecular scientists to explore the effects of a wide range of potential moieties at each of the four more variable molecule locations in an attempt to create 'wondafloxacin'; however, it is essential that an overall molecular balance be maintained and that each substituent should contribute to antibacterial activity in some form. A detailed examination of the quinolone pharmacore may help to explain some of the features found on the quinolones available currently, as well as those under development.

\section{Position 1}

It was realised that a cyclopropyl moiety (e.g., as seen in ciprofloxacin and sparfloxacin) at this point conferred significant activity against gram-negative bacteria. The groups 2,4-difluorophenyl (temafloxacin) and t-butyl (BMY 40062) are slightly less potent; however, the 2,4-difluorophenyl group heightens activity against anaerobes [5].

\section{Position 5}

Considerable changes have been concentrated at this position in an effort to improve the activity of the fluoroquinolones against gram-positive bacteria. The most advanced compounds that carry significant changes at position 5 are sparfloxacin and PD 124816 , both of which carry an $-\mathrm{NH}_{2}$ moiety, whereas OPC 17116 (grepafloxacin) possesses a $-\mathrm{CH}_{3}$ molecule [5].

\section{Position 7}

This is one of the most influential points on the molecule and, almost without exception, the possession of a five- or six-membered nitrogen heterocycle at this position has improved a molecule's activity and pharmacokinetic profile. The most popular heterocycles employed at position 7 are aminopyrrolidines and piperazines. Anti-bacterial agents that contain an aminopyrrolidine moiety are tosufloxacin, clinafloxacin, Du6859a, Bay 3118 and several compounds from the Parke-Davis company [6]. In contrast, the piperazine substituent is found on ciprofloxacin, lomefloxacin, temafloxacin, sparfloxacin and BMY 40062. The former moiety tends to confer better activity against gram-positive bacteria, whereas piperazine offers improved activity against gram-negative bacteria [5]. Substitution with an alkyl moiety will improve gram- 
positive potency and lengthen the serum half-life; this type of change has been employed in lomefloxacin, sparfloxacin and several other quinolones now under development.

\section{Position 8}

Various substituents at this position have led to marked improvements in activity, particularly against anaerobic bacteria; the most useful groups employed on this position are $\mathrm{CF}, \mathrm{CCl}$ and $\mathrm{COMe}$.

Examples of specific substituents to the quinolone pharmacore are shown in Fig. 2. In addition to the role that certain moieties may play in enhancing activity against specific groups of bacteria and altering the pharmacokinetic properties of a drug, these chemical modifications also play a significant role in the specific interaction of these compounds with man.

\section{Adverse effects}

Fluoroquinolones are known to produce various sideeffects in man and certain test animal species. Perhaps the most frequent side-effects are those affecting the gastrointestinal system, such as nausea, vomiting, gastric irritation and, occasionally, diarrhoea. Despite the transient unpleasant consequences of these effects, no specific structure has yet been identified as their main cause and thus no quinolone has yet been designed which is free of gastrointestinal effects. Adverse dermatological symptoms, such as skin rash or pruritis, occur in $0.5-3 \%$ of patients [7], and may be consequences of histamine release, as has been suggested for BMY 40062 [8]. An animal model developed to ascertain the effect of alkylation of the piperazinyl at position 8 showed this alkylation to be beneficial, [5] and it appears that such an animal model may be of value in examining future quinolones.

\section{Position 1}

$\begin{array}{ll}\mathrm{C}_{3} \mathrm{H}_{5} & \text { 2,4-di Fph- } \\ \text { ciprofloxacin } & \text { tosufloxacin } \\ \text { sparfloxacin } & \text { temafloxacin }\end{array}$

\section{Position 5}

$\begin{array}{lll}\mathrm{H}- & \mathrm{NH}_{2}^{-} & \mathrm{CH}_{2} \\ \text { ciprofloxacin } & \text { sparfloxacin } & \text { OPC 17116 } \\ \text { tosufloxacin } & \text { PD124816 } & \text { (grepafloxacin) } \\ \text { many others } & & \end{array}$
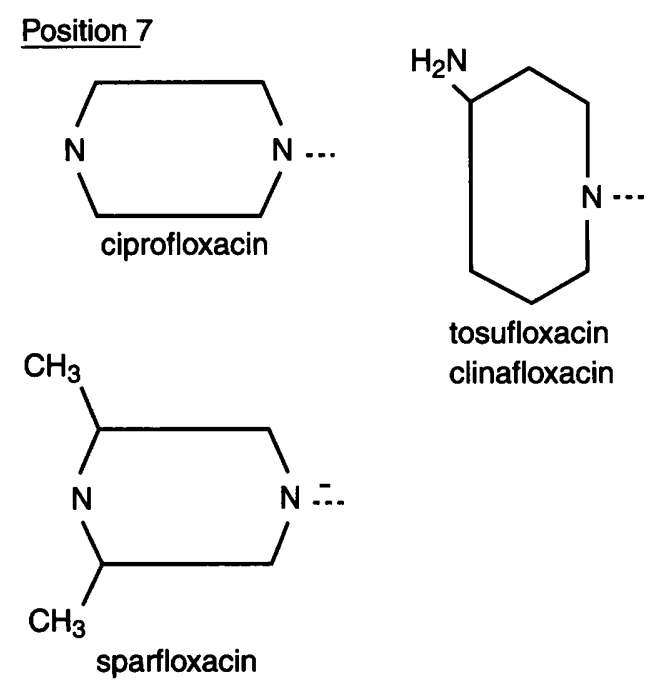

tosufloxacin clinafloxacin

\section{Position 8}

$\mathrm{CH} \quad \mathrm{CF} \quad \mathrm{CCl} \quad \mathrm{COMe}$

ciprofloxacin lomefloxacin Du6859a AM1155 temafloxacin sparfloxacin Bay 3118 Q-35 grepafloxacin Y-26611 clinafloxacin

Fig. 2. Examples of specific substituents to the quinolone pharmacore.

Table 2. Relative degree of GABA inhibition and incidence of spontaneously reported CNS events in the UK*

\begin{tabular}{|c|c|c|c|}
\hline Agent & Position 7 & $\begin{array}{c}\text { Degree of } \\
\text { GABA inhibition }\end{array}$ & $\begin{array}{c}\text { Incidence of CNS } \\
\text { side-effects }\end{array}$ \\
\hline Ciprofloxacin & $\begin{array}{l}N \\
L\end{array}$ & High & $\begin{array}{c}62 / 10^{6} \text { scrips } \\
\text { Dizziness }\left(14 / 10^{6}\right) \\
\text { Insomnia }\left(3 / 10^{6}\right)\end{array}$ \\
\hline Norfloxacin & $\begin{array}{l}N \\
L\end{array}$ & High & $\begin{array}{c}49 / 10^{6} \text { scrips } \\
\text { Dizziness }\left(32 / 10^{6}\right) \\
\text { Insomnia }\left(3 / 10^{6}\right)\end{array}$ \\
\hline Ofloxacin & $\mathrm{CH}_{3} \mathrm{~N}$ & Low & $\begin{array}{c}89 / 10^{6} \text { scrips } \\
\text { Dizziness }\left(25 / 10^{6}\right) \\
\text { Insomnia }\left(30 / 10^{6}\right)\end{array}$ \\
\hline
\end{tabular}

${ }^{*}$ See references 5 and 7. 
Effects within the central nervous system (CNS) are generally some of the more frequent adverse consequences of quinolone therapy [7]. It is convenient to categorise the quinolones into those that act directly on the CNS receptors, and those that exert an effect when given with other agents. The direct effects include headache, sleep disorders, dizziness, agitation and, very occasionally, convulsions. These effects correlate with the quinolone binding to the receptors for $\gamma$-aminobutyric acid (GABA) in the brain, thereby preventing normal binding of GABA and heightening CNS stimulation. Several models have been developed to measure the interactions of quinolones with GABA receptors. From these models it transpires that the substituent at position 7 has most effect on the direct CNS interaction. Curiously, the predicted level of GABA interaction does not always correlate with the frequency at which adverse events are reported [9]. Table 2 shows the relative degree of GABA inhibition and the frequency of spontaneous adverse CNS events reported in the UK.

One of the earliest adverse events recognised with quinolones was arthropathic damage in weight-bearing joints of animals, particularly canine species [10]. These changes were seen most often after prolonged exposure to high doses. Certain quinolones seem to be more likely to cause these changes, but insufficient evidence from substituent modifications has been gathered. Thus it is assumed that these arthropathies are class effects but, fortunately, there have been very few instances of irreversible joint damage in children treated with quinolones [11].

The adverse event that has caused most recent attention is phototoxicity [12]. All fluoroquinolones can cause a non-immunogenic phototoxic reaction, but there are clearly some compounds that cause the problem more frequently and more severely. In an effort to predict how new agents will react, an animal model, the mouse phototolerance system, has been developed [13]. This model can incorporate all the influencing factors, such as photoreactivity, half-life, skin toxicity and skin penetration. It has been shown that the possession of a halogen, such as fluorine or chlorine, at position 8 leads to the highest incidence of phototoxicity. Table 3 shows some of the current and imminent quinolones in terms of the least concentration required to cause a phototoxic response in the mouse model.

The marked consequences of a severe phototoxic reaction have resulted in the termination of development of a series of fluoroquinolones, whilst lomefloxacin (Maxaquin; Searle) was the centre of attention in the USA of an FDA inquiry and subsequent 'pink letter' [14] to all doctors warning of the phototoxic and photocarcinogenic properties of the drug. In the period Oct. 1994-June 1995, two other government agencies, in Japan and France,
Table 3. Comparison of drug dosages associated with photoxicity in the mouse model [5]

\begin{tabular}{|c|c|c|}
\hline Quinolone & $\begin{array}{c}\mathbf{X}_{\mathbf{8}} \\
\text { substituent }\end{array}$ & $\begin{array}{l}\text { Dosage associated } \\
\text { with phototoxicity } \\
(\mathrm{mg} / \mathrm{kg})\end{array}$ \\
\hline Ciprofloxacin & $\mathrm{CH}$ & $>300$ \\
\hline Ofloxacin & COR & $>300$ \\
\hline Norfloxacin & COR & $>300$ \\
\hline Lomefloxacin* & CF & 10 \\
\hline Clinafloxacin ${ }^{\dagger}$ & $\mathrm{CCl}$ & 18 \\
\hline Sparfloxacin & $\mathrm{CF}$ & 18 \\
\hline $\begin{array}{l}\text { Des-amino } \\
\text { sparfloxacin }\end{array}$ & CF & $<10$ \\
\hline Bay $3118^{\dagger}$ & $\mathrm{CF}$ & 3 \\
\hline
\end{tabular}

*Subject of FDA doctor 'warning letter'.

${ }^{\dagger}$ Development discontinued.

issued warnings to doctors regarding the phototoxic potential of sparfloxacin $[15,16]$. In these two countries, 52 and 208 cases of phototoxicity, respectively, were reported spontaneously to the health authorities within the first 8 months of clinical use. These reports corroborate the mouse phototolerance model findings.

In addition to specific activity, pharmacokinetic and side-effect features, certain interactions have been shown to be associated closely with some moieties. Interaction with theophylline or non-steroidal antiinflammatory drugs (NSAIDs) are among the bestrecognised clinically significant situations. For the NSAID interaction, position 7 seems to have the greatest significance, with unsubstituted piperazines (ciprofloxacin, enoxacin, norfloxacin) showing the greatest effect. Alkylated piperazines and pyrrolidines have less effect. Despite these strong in-vitro and model interactions, there are few NSAID-induced adverse CNS events [17].

So far as the theophylline interaction is concerned, this compound is metabolised by the cytochrome P450 enzymes. These enzymes are inhibited by some quinolones, thus leading to an accumulation of theophylline and possible toxic reactions such as convulsions. Again, the position 7 substituent has a major bearing on this interaction, although not exclusively, as the moieties at positions 1 and 8 also have an effect. It is also important to note that quinolones which are metabolised hepatically may lead to metabolites that can also interact with theophylline, e.g., the M-1 metabolite of ciprofloxacin [5].

In summary, although there is now a profound understanding of the basic quinolone molecule and precisely what effects will be exerted when specific substituents are added at certain positions, the 'ultimate' molecule with a very broad spectrum of activity, an excellent pharmacokinetic profile (i.e., long half-life and vast volume of distribution) and an acceptable safety profile still seems to be elusive amongst the fluoroquinolone molecules of today. 

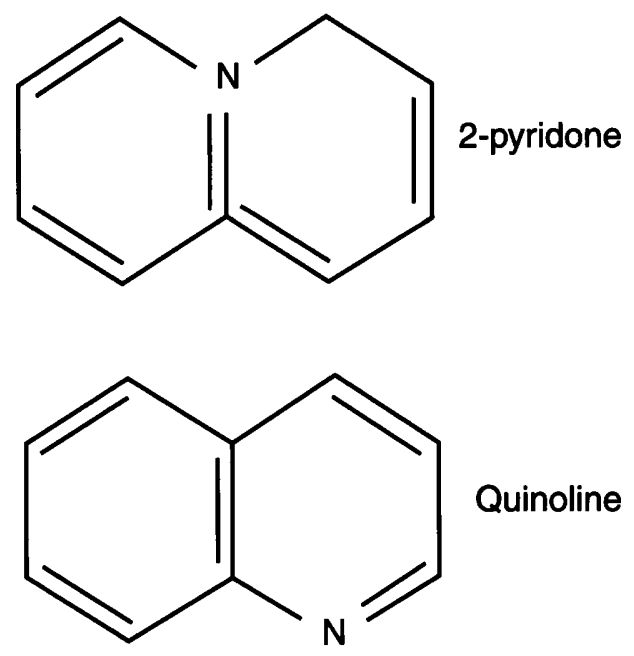

Fig. 3. Structure of the 2-pyridone molecule in comparison with quinoline.

\section{Possible future developments}

Of the fluoroquinolones currently licensed, ciprofloxacin has the broadest spectrum of activity, while ofloxacin is well-distributed into tissues. Both of these compounds are tolerated well by man. A variety of unforeseen effects, including the temafloxacin syndrome, have resulted in the disappearance of many potential 'block-busters'. Therefore, it may be time to look for alternative molecules that also attack bacteria via DNA gyrase. Such a group of molecules were 'showcased' at the 1994 Interscience Conference on Antimicrobial Agents and Chemotherapy by the Abbott company. This new group - 2-pyridones (Fig. 3) - act on DNA gyrase $[18,19]$ and, probably, topoisomerase IV (which is a homologue of DNA gyrase). This enzyme appears to play a role in the separation of the daughter DNA molecules after replication. The precise interplay between quinolones and this enzyme is unknown. Of these new 2-pyridones, ABT 719 has considerable antibacterial activity, including gram-positive bacteria and anaerobes. It possesses greater activity than the best current gram-negative quinolone, ciprofloxacin, against both enterobacteria and pseudomonads. Animal models have shown ABT719 (also known as A-86719.1) to be effective in vivo in several systemic infections [19]. It remains to be seen whether the 2-pyridones are set to take over from the quinolones, which in the space of 10 years have become some of the most relied-upon antibiotics throughout the world.

\section{References}

1. Lesher GY, Froelich ED, Gruet MD, Bailey JH, Brundage RP. 1,8 Naphthyridine derivatives. A new class of chemotherapeutic agents. J Med Pharm Chem 1962; 5: 1063-1068.
2. Norris S, Mandell GL. The quinolones: history and overview. In: Andriole VT (ed) The quinolones. London, Academic Press. 1988: 1-22.

3. Koga $\mathrm{H}$, Itoh A, Murayama S, Suzue S, Irikura T. Structureactivity relationships of antibacterial 6,7- and 7, 8-disubstituted 1-alkyl-1, 4-dihydro-4-oxoquinolone-3-carboxylic acids. $J$ Med Chem 1980; 23: 1358-1363.

4. Mitscher LA, Devasthale P, Zavod R. Structure-activity relationships. In: Hooper DC, Wolfson JS (eds) Quinolone antimicrobial agents. Washington DC, American Society for Microbiology, 2nd edn. 1993: 3-51.

5. Domagala JM. Structure-activity and structure-side-effect relationships for the quinolone antibacterials. $J$ Antimicrob Chemother 1994; 33: 685-706.

6. Sanchez JP, Domagala, JM, Hagen SE et al. Quinolone antibacterial agents. Synthesis and structure-activity relationships of 8-substituted quinolone-3-carboxylic acids and 1,8naphthyridine-3-carboxylic acids. J Med Chem 1988; 31: 983991.

7. Ball AP, Tillotson GS. Tolerability of fluoroquinolones antibiotics: past, present and future. Drug Safety 1995; 13: 343358.

8. Remuzon P, Bouzard D, Guiol C, Jacquet JP. Fluoronaphthyridines as antibacterial agents. 6. Synthesis and structureactivity relationships of new chiral 7-(1-, 3-, 4-, and 6-methyl2,5-diazabicyclo [2.2.1] heptan-2-yl) naphthyridine analogues of 7-[(IR, 4R)-2,5-diazobicyclo [2.2.1.] heptan-2-yl)-1-(1,1diamethylethyl)-6-fluoro-1,4-dihydro-4-oxo-1,8-naphthyridine-3carboxylic acid. Influence of the configuration of blood pressure in dogs. A quinolone-class effect. $J$ Med Chem 1992; 35 2898-2909.

9. Janknegt R, Hekster YA. Developments in quinolones. Bacteriology, pharmacokinetics and initial clinical experience of several investigational quinolone derivatives. Pharm Weeklbl [Sci] 1989; 11: 33-43.

10. Ingham B, Brentnall DW, Dale EA, MacFadzean JA. Arthropathy induced by antibacterial fused N-alkyl-4-pyridone-3carboxylic acids. Toxicol Lett 1977; 1: 21-26.

11. Schaad UB, Salam MA, Aujard Y et al. Use of fluoroquinolones in paediatrics: concensus report of an International Society of Chemotherapy commission. Pediatr Infect Dis $J$ 1995; 14: 1-9.

12. Paton DH, Reeves DS. Adverse reactions to fluoroquinolones. Adv Drug React Bull 1992; 153: 575-578.

13. Sesnie JC, Heifetz CL, Joanides ET, Malta TE, Shapiro MA. Comparative phototoxicities of quinolones in a mouse phototolerance model. In: Proceedings of the 30th International Conference on Antimicrobial Agents and Chemotherapy. Washington DC, American Society for Microbiology. 1990: abstract 399 .

14. Food and Drug Administration Anti Infectives Drugs Advisory Committee. Review of phototoxicity issue with lomefloxacin and other fluoroquinolones. In: Proceedings of the 46th Meeting of the Drugs Advisory Committee. Washington DC, Food and Drug Administration. 1994.

15. Ministry of Health and Welfare Pharmaceutical Affairs Dept. Sparfloxacin and photosensitivity. In: Information on Adverse Reactions to Drugs No. 127. Tokyo, Ministry of Health and Welfare. 1994: 2-8.

16. Bouchery D. Eviter toute activite a l'exterieur. Paris, National Board of Pharmacovigilance, Information Medecin. 1995.

17. Janknegt R. Drug interactions with quinolones. $J$ Antimicrob Chemother 1990; 26 Suppl D: 7-29.

18. Chin NX, Chu D, Huang HB, Neu HC. A-86719.1, a new class DNA gyrase inhibitor, its time-killing activity, postantibiotic effect and assay condition effect. In: Proceedings of the 34th International Conference on Antimicrobial Agents and Chemotherapy. Washington DC, American Society for Microbiology. 1994: abstract F51.

19. Alder JP, Meulbroek JM, Shipkowitz NL. Efficacy of A86719.1 , a novel 2-pyridone gyrase inhibitor, for treatment of systemic, lung and abscess infections in mice and rats. In: Proceedings of the 34th International Conference on Antimicrobial Agents and Chemotherapy. Washington DC, American Society for Microbiology. 1994: abstract F53. 